\title{
Chinese expert consensus-based guideline on assessment and management of asthma exacerbation
}

\author{
Jiangtao Lin ${ }^{1}$, Bin Xing ${ }^{1}$, Ping Chen ${ }^{2}$, Mao Huang ${ }^{3}$, Xin Zhou ${ }^{4}$, Changgui $\mathrm{Wu}^{5}$, Dong Yang ${ }^{6}$, \\ Kaisheng Yin ${ }^{3}$, Shaoxi Cai ${ }^{7}$, Xiaoming Cheng ${ }^{8}$, Chuangli Hao9, Changzheng Wang ${ }^{8}$, Chuntao Liu ${ }^{10}$; \\ on behalf of China Asthma Alliance
}

\begin{abstract}
${ }^{1}$ Department of Respiratory and Critical Care Medicine, China-Japan Friendship Hospital, Beijing 100029 , China; ${ }^{2}$ Department of Respiratory Medicine, General Hospital of Shenyang Military Region, Shenyang 110015, China; ${ }^{3}$ Department of Respiratory Medicine, First Affiliated Hospital of Nanjing Medical University, Nanjing 210029, China; ${ }^{4}$ Department of Respiratory Medicine, First People's Hospital, Shanghai Jiao Tong University, Shanghai 200080, China; ${ }^{5}$ Department of Respiratory Medicine, Xijing Hospital of Fourth Military Medical University, Xi'an 710032, China; ${ }^{6}$ Department of Respiratory Medicine, Zhongshan Hospital, Fudan University, Shanghai 200032, China; ${ }^{7}$ Department of Respiratory Medicine, Nanfang Hospital of Southern Medical University, Guangzhou 510515, China; ${ }^{8}$ Department of Respiratory Medicine, Xinqiao Hospital of Third Military Medical University, Chongqing 400037, China; ${ }^{9}$ Department of Respiratory Medicine, Children's Hospital of Soochow University, Suzhou 215000, China; ${ }^{10}$ Department of Respiratory Medicine, West China Hospital of Sichuan University, Chengdu 610041, China

Correspondence to: Prof. Jiangtao Lin, MD, PhD. China-Japan Friendship Hospital, Beijing 100029, China. Email: jiangtao_1@263.net; Prof. Xin Zhou, MD, PhD. First People's Hospital, Shanghai 200080, China. Email: xzhou53@163.com.
\end{abstract}

Submitted Jun 15, 2019. Accepted for publication Dec 11, 2019.

doi: $10.21037 /$ jtd.2019.12.67

View this article at: http://dx.doi.org/10.21037/jtd.2019.12.67

The goal of management for bronchial asthma (referred to as asthma below) is to achieve overall control of the condition, including control of current symptoms and reduction on future risks. Asthma exacerbation as one of critical component of the future risks $(1,2)$, may induce a variety of harms to the host, necessitate additional use of medical resources, impose serious socioeconomic burdens, and represent a significant cause of asthma-related disability and mortality (3). As such, prevention and reduction of the asthma exacerbation are of important relevance in improving the overall control of asthma (2-5).

In diagnosing and treating asthma exacerbation, the expertise of clinicians in Chinese hospitals of varied levels has currently been compromised by less standard practicing due to a number of subjective or objective factors. This also results in increased medical cost (3). To standardize the practicing, renew the understandings on diagnosis and treatment, and improve the care for asthma exacerbation, the China Asthma Alliance (CAA) has developed this consensus document based on in-depth discussion among a summoned panel of Chinese experts in related fields, with reference to relevant international guidelines $(1,6,7)$ and focused articles appearing within and outside the country in the past few years. The document is desired to offer guidance and evidence for diagnosis, treatment, prevention and management of asthma exacerbation in clinical settings, as well as related studies.

\section{Definition}

Asthma exacerbation is defined as sudden onset of symptoms like wheezing, shortness of breath, cough and chest tightness, or worsening of the current symptoms, typically associated with dyspnea and characterized by reduced expiratory flow, and usually requires adjustment of medications $(1,6,7)$.

Although sometimes it can be an initial manifestation, asthma exacerbation more likely occurs in patients with confirmed asthma, and in most of times, is triggered by exposure to allergens or irritants, respiratory infections or poor patient adherence to controller medications $(5,7)$, despite unclear predisposing factors in fewer patients. Occasionally, severe exacerbation may be seen in mild or well-controlled asthma $(8,9)$. 


\section{Risk factors and predisposing factors}

\section{Risk factors}

Patients with risk factors below are more susceptible to acute exacerbation (1), including (I) uncontrolled asthma symptoms; (II) excessive dosing of short-acting beta-2 receptor agonists (SABAs); (III) insufficient use of inhaled corticosteroids (ICS), such as naivety, poor medication adherence, and invalid inhalation techniques of ICS; (IV) low forced expiratory volume in the first second $\left(\mathrm{FEV}_{1}\right)$, especially when $\mathrm{FEV}_{1}<60 \%$ predicted; (V) uncontrolled mental disorders; (VI) poverty or low income; (VII) tobacco smoking; (VIII) comorbidities such as obesity, allergic rhinitis, and food allergies; (IX) sputum/blood eosinophilia with elevated level of fractional exhaled nitric oxide (FeNO); (X) pregnancy.

\section{Predisposing factors}

Predisposing factors refer to factors that predispose exacerbation or worsening of asthma symptoms. A number of predisposing factors feature seasonality, and are linked to respiratory infections, allergen inhalation, and the weather. In fact, the onset of asthma exacerbation as related to seasonality was shown in a retrospective study in 29 Chinese provinces/metropolises where the hospital admissions due to asthma exacerbation peaked in March and September each year (10), probably arising from seasonal changes.

\section{Respiratory infections}

Infections with a diversity of viruses, including rhinovirus, influenza virus, and respiratory syncytial virus (RSV), as well as bacteria, may trigger asthma exacerbation (11). A multicenter, retrospective survey with large sample size in Chinese adults showed that acute upper airway infection was the first leading predisposing factor for asthma exacerbation-related hospital admissions, and accounted for $42.3 \%$ of all asthma exacerbation cases (12). In children, this figure can be much higher (13).

\section{Allergen inhalation}

Environment allergens as major triggers of asthma (11), are present indoors and outdoors. Indoor allergens include dust mites, pet dander and cockroaches; outdoor allergens include pollens and fungi. Dust mites are the major allergens in Chinese asthma patients. In this country, pollens from Artemisia and Ragweed are the most frequent sensitizing allergens. Seasonal pollens may be the culprit for September peak of asthma exacerbation-related hospital admissions in the Chinese population (10).

\section{Tobacco smoking}

Smoking closely correlates with asthma onsets (14), and adds to difficulty asthma control by expediting the lung function decline (15) and attenuating treatment response to inhaled/systemic corticosteroids (referred to as corticosteroids below) in asthma patients $(16,17)$.

\section{Air pollution}

Outdoor pollutants (ozone, sulfur dioxide, nitrogen dioxide and inhalable particulate matter) and indoor pollutants (biofuel fumes) cause asthma onsets $(18,19)$.

\section{Weather}

Cold air, and changes in atmospheric humidity and pressure may trigger asthma, with significantly more onsets in regions with wider temperature range, higher humidity or lower atmospheric pressure.

\section{Occupational factors}

Five percent to $25 \%$ of asthma cases arose from occupational chemicals at workplace. Occupational sensitizers are one of the predisposing factors to asthma (20). There is a wide range of occupational sensitizers that may cause asthma onsets, mainly found in flour processing, stock farming, greenhouse planting, and industry manufacturing of plastics, fiber, paints, and rubber (21).

\section{Exercises}

Physical exercise is a common trigger to asthma, probably underlain by hyperventilation-induced bronchospasm (22), and frequently affects teenagers, athletes and patients with poorly controlled asthma (23).

\section{Medications}

These apply to asthma related to drug allergies [nonsteroidal anti-inflammatory drugs (NSAID, e.g., aspirin), antibacterials (e.g., penicillin, and sulfonamides), and contrast agents] and asthma related to adverse drug reactions (e.g., beta-receptor antagonists).

\section{Foods and food additives}

Food-triggered asthma typically affects children and infants, and may include flour, eggs, milk, seafood (e.g., fish, shrimps and crabs), meat products, bean products, and nuts. Certain food additives may also induce asthma. 
Table 1 Mechanisms of the asthma exacerbation according to triggering factors

\begin{tabular}{lll}
\hline Triggers & Airway responses & Mechanisms \\
\hline Viruses & $\begin{array}{l}\uparrow \text { Lower respiratory tract damage, neutrophilic } \\
\text { bronchitis }\end{array}$ & Activation of epithelial chemokines, no interferon-beta response \\
Allergens & $\uparrow$ Eosinophil response & Th2-activated release of interleukin-5 \\
Occupational factors & $\uparrow$ Eosinophilic and/or neutrophilic bronchitis & Sensitization \\
Environmental pollution & Neutrophilic bronchitis & Activation of epithelial cells/macrophage activating factors \\
Aspirin & Severe bronchospasm & $\begin{array}{l}\text { Altered arachidonic acid metabolism via the 5-lipoxygenase } \\
\text { pathway, causing excessive leukotriene production }\end{array}$ \\
\hline
\end{tabular}

Th, T helper cell.

Table 2 Cellular mechanisms underlying rhinovirus-induced sensitization in patients with asthma

\begin{tabular}{lll}
\hline Action & Healthy individuals & Asthma patients \\
\hline $\begin{array}{l}\text { During rhinovirus binding } \\
\text { ICAM-1 expression }\end{array}$ & Low & High \\
Epithelial integrity & Intact & Damaged \\
After rhinovirus binding & & \\
Interferon-beta response & Early, effective & Defective \\
Cytolysis and apoptosis & Cell apoptosis & Cytolysis, enhanced by apoptosis of damaged cells \\
Release of inflammatory mediators & Present & Enhanced \\
Immune response & & \\
Neutrophil infiltration & Present & Enhanced \\
Th1 response & Effective (interferon-gamma) & Defective (interferon-gamma) \\
\hline
\end{tabular}

ICAM, intercellular adhesion molecule; Th, T helper cell.

\section{Mental factors}

Anxiety and serious emotional fluctuations may induce asthma (24).

\section{Endocrine considerations}

Some women may experience worsening of asthma symptoms during their periods and pregnancy $(25,26)$, which may be related to altered hormone levels.

\section{Pathogenesis and pathophysiology}

\section{Pathogenesis}

Asthma exacerbation is an excessive reaction of the lower airway to environmental exposure. A sudden deterioration of the chronic airway inflammation is central to asthma exacerbation, accompanied by worsening of airflow obstruction and airway responsiveness. Asthma exacerbations are often triggered by viral infections, allergens, environmental pollution, occupational irritation, and medications (e.g., aspirin). With different triggering factors, asthma exacerbations vary in airway inflammatory responses and their underlying immunological mechanisms (Table 1). Respiratory viral infections, particularly with rhinovirus, are the most common and sometimes a single etiology of asthma onsets (see Table 2 for pathogenesis). In virus-induced asthma exacerbation, the induced sputum levels of neutrophils and neutrophil elastase may be elevated; paralleled with increased level of lactate dehydrogenase, lower airway epithelial necrosis and airway hyperresponsiveness may be present (27). Fungi, Aspergillus spores in particular, may directly aggravate bronchial epithelial damage and contribute to airway hyperresponsiveness, leading to asthma exacerbation. A 


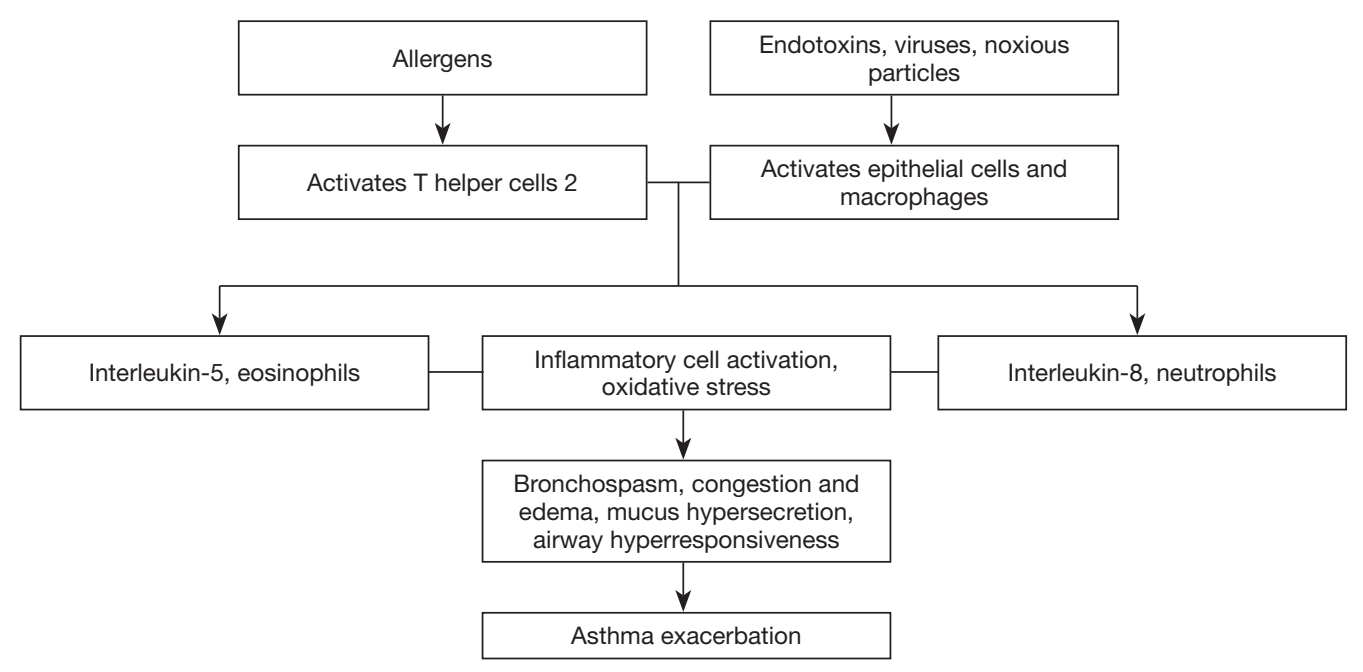

Figure 1 Mechanisms underlying asthma exacerbation induced by environmental factors.

blood count of eosinophils $>0.4 \times 10^{9} / \mathrm{L}$ in asthma patients is associated with onset of asthma exacerbation, suggesting that blood eosinophils can be used as a biomarker (28). Airway inflammation as the pathophysiological basis, plus immune-inflammatory response as the major pathogenic mechanism, interplays with airflow obstruction and hyperresponsiveness and ultimately leads to asthma exacerbation, only that the airway inflammation differs across triggers, i.e., allergens activate T-help 2 (Th2) cells which in turn release interleukin (IL)-5 and cause eosinophilic inflammation, whereas endotoxins, viruses, harmful particles activate airway epithelial cells and macrophages to release IL-8 and cause neutrophilic inflammation. Activation of inflammatory cells and the oxidative stress result in asthma exacerbation (Figure 1).

\section{Pathology and pathophysiology}

The pathology of asthma exacerbation mainly involves acute aggravation of airway inflammation (including airway epithelial damage, bronchomucosal hyperemia and edema, airway hyper-secretion and smooth muscle contraction) which has been proposed to be allergic, neurogenic, or viral infection-induced, by a few disciplines. Resulting from airway inflammation, the pathophysiology of asthma exacerbation is mainly manifested by airway hyperresponsiveness, deteriorated airway stricture and airflow limitation, and neural receptor dysfunction, which contribute to ventilatory impairment, clinical symptoms such as wheezing, or worsening of the symptoms, with or without a set of pathophysiological changes related to hypoxia. The pathology and pathophysiology of asthma exacerbation are shown in Figure 2.

\section{Assessment of asthma exacerbation}

Mostly, asthma exacerbation is preceded by early signs. A survey on ambulatory asthmatics in 30 provinces/ metropolises in China showed that early signs of asthma exacerbation were present in $82.5 \%$ of the interviewees prior to their latest episode, with cough, chest tightness and shortness of breath being the first three leading symptoms by frequency (29). Identifying the preceding signs of asthma early would favor reducing asthma attacks (5).

Asthma exacerbation varies in severity, and the progression of onset as well-usually over hours or days, but occasionally it can become life-threatening within minutes. It is noteworthy that severe asthma exacerbation may occur in patients with mild or well-controlled asthma.

Low expiratory flow features the worsening of impaired lung function during asthma exacerbation. The severity of asthma exacerbation is rated according to clinical symptoms, lung function, and arterial blood gas analysis (Table 3).

In clinical settings, asthma exacerbation needs to be differentiated from wheezing and dyspnea caused by a wide spectrum of conditions, including acute left ventricular dysfunction, acute exacerbation of chronic obstructive pulmonary disease, acute pulmonary embolism, upper airway obstruction, primary bronchogenic carcinoma, benign bronchial tumor, allergic bronchopulmonary 


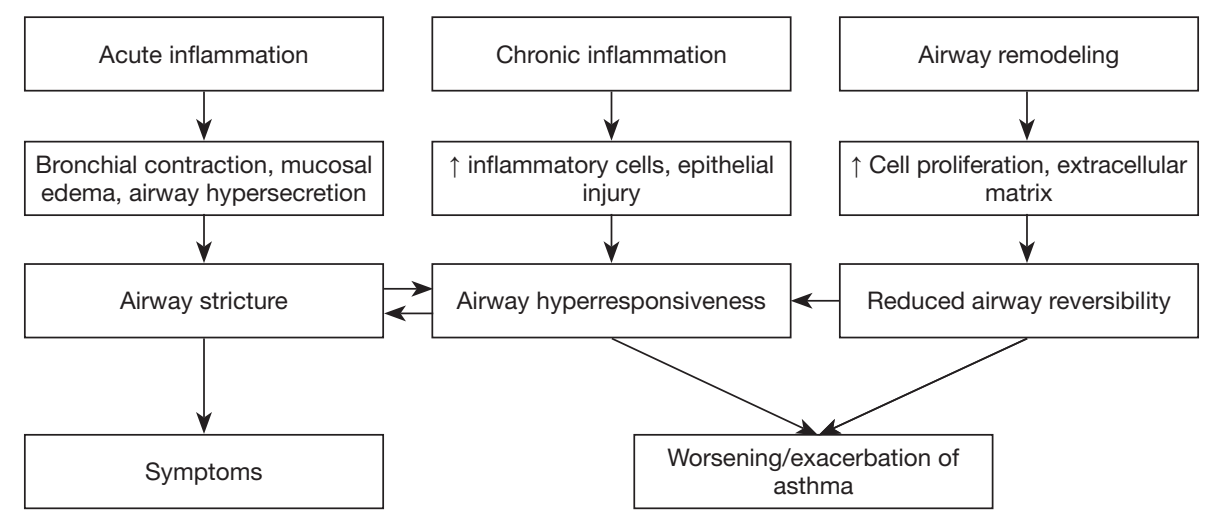

Figure 2 Pathological and pathophysiology in asthma exacerbation.

Table 3 Severity rating of asthma exacerbation

\begin{tabular}{|c|c|c|c|c|}
\hline Clinical characteristics & Mild & Moderate & Severe & Life-threatening \\
\hline Body posture & Able to lie down & Prefers sitting & Sits hunched forward & \\
\hline Speech & Talks in sentences & Talks in words & Talks in syllables & Unable to talk \\
\hline Sweating & Absent & Present & Profuse & \\
\hline Respiratory rate & Slightly fastened & Fastened & Often $>30$ times $/ \mathrm{min}$ & \\
\hline $\begin{array}{l}\text { Involvement of accessory respiratory } \\
\text { muscles and three-concave sign }\end{array}$ & Usually absent & Sometimes & Often & Paradoxical breathing \\
\hline Paradoxical pulse & Absent & Sometimes & Often (in adults) & $\begin{array}{l}\text { Absent, indicating } \\
\text { respiratory muscle fatigue }\end{array}$ \\
\hline $\begin{array}{l}\text { Percentage of PEF predicted or personal } \\
\text { best after initial bronchodilator treatment }\end{array}$ & $>80 \%$ & $60 \%-80 \%$ & $\begin{array}{l}<60 \% \text { or } 100 \mathrm{~L} / \mathrm{min} \text { or } \\
\text { action time }<2 \mathrm{~h}\end{array}$ & \\
\hline $\mathrm{PaO}_{2}(\mathrm{mmHg})$ at rest & Normal & $\geq 60$ & $<60$ & $<60$ \\
\hline $\mathrm{PaCO}_{2}(\mathrm{mmHg})$ at rest & $<45$ & $\leq 45$ & $>45$ & $>45$ \\
\hline $\mathrm{SaO}_{2}(\%)$ at rest & $>95$ & $91-95$ & $\leq 90$ & $\leq 90$ \\
\hline $\mathrm{pH}$ value & & & & Lowered \\
\hline
\end{tabular}

The severity of asthma exacerbation is determined when part but not all of the clinical characteristics to a given classification are met. $1 \mathrm{mmHg}=0.133 \mathrm{kPa}$. PEF, peak expiratory flow rate; $\mathrm{PaO}_{2}$, partial arterial pressure of oxygen; $\mathrm{PaCO}_{2}$, partial arterial pressure of carbon dioxide; $\mathrm{SaO}_{2}$, arterial oxygen saturation. 
aspergillosis, exogenous allergic alveolitis, eosinophilic granulomatous vasculitis, hyperventilation syndrome, and spontaneous pneumothorax.

\section{Treatment}

\section{Treatment goals and principles of severity-based management for asthma}

\section{Treatment goals}

The severity of asthma exacerbation is rated as mild, moderate, severe and life-threatening. Generally, the treatment goals focus on, as quickly as possible, relieving the symptoms, resolving bronchospasm, improving hypoxia, maintaining lung function, minimizing future risks of deterioration or re-exacerbation, and preventing against complications.

\section{Principles of severity-based management}

Self-management with observance of an 'asthma action plan' is feasible for mild and part of moderate acute exacerbations. Patients should seek medical aids in hospitals if they fail to respond or their condition persists worsening after 2 days from the initial treatment. Even if the asthma symptoms relieve, the patients are advisable to undergo hospital assessment of asthma control, investigation for triggers of the exacerbation, and adjustment of treatment regimen (1,30). For severe and life-threatening cases, immediate hospital visits are mandatory, and during the waiting or transferring, inhaled salbutamol (with or without ipratropium bromide), and doubled to quadrupled daily dose of ICS or oral corticosteroids can be considered for rescue treatment.

\section{General supportive treatment}

When asthma exacerbation occurs, initial treatment should include removing the patient from allergens and avoiding further contact with and exposure to triggering or risk factors. Oxygen therapy should be given for those with difficulty breathing (1).

\section{Home and community management}

Home and community management is the initial part of treatment for acute exacerbation, with which, mild and moderate acute exacerbation can become relieved. The management mainly involves repeated inhalation of rapid- acting bronchodilator, or combination low-dose ICS/ formoterol. Inhaled SABA is most commonly the first-line rapid-acting bronchodilator, given 2 to 4 puffs initially, repeated every 20 minutes during the first hour, and then assessed for the treatment response. Thereafter, the dosing of SABA may be titrated to 2 to 4 puffs every 3 to 4 hours for patients with mild exacerbation, and 6 to 10 puffs every 1 to 2 hours for those with moderate exacerbation of asthma. SABAs may be delivered via spacers or nebulizers. The nebulization therapy may start intermittent (every 20 minutes apart) or continuous, and then be given intermittently as needed (once every 3 to 4 hours). Combination use of SABA and anticholinergics (ipratropium bromide) may result in more efficient bronchodilatory actions, greater improvement of lung function, and fewer hospital admissions due to asthma exacerbation. The dose of ipratropium bromide is 2 puffs via inhalation or $500 \mu \mathrm{g}$ via nebulization, given once every 6 hours. Patients who use combination low-dose ICS/formoterol as a controller treatment may take extra 1 to 2 puffs of the agent per time, totaling up to no more than 8 to 12 puffs per day $(6,30)$.

The dose of ICS should be increased by at least two times of daily use or up to a maximum of $1,600 \mu \mathrm{g} / \mathrm{d}$ budesonide or equivalent. When accessible, nebulized inhalation of budesonide suspension (1 to $2 \mathrm{mg}$, thrice daily) is recommended. Systemic corticosteroids should be added for those with poor response, especially, in whom the acute exacerbation occurs despite controller treatments. Owing to the fast absorption and high bioavailability, as well as comparable performances to intravenous steroids, oral prednisone ( 30 to $50 \mathrm{mg}$ ) or equivalent can be used as a first-line treatment for acute exacerbation, unless ingestion is impossible for the patient because of extreme shortness of breaths or vomiting $(31,32)$.

If accessible, oxygen therapy at home may be initiated. High flow oxygen therapy is recommendable at the beginning, but should be monitored and titrated against oximetry to maintain saturation at $93 \%$ to $95 \%$.

Patients who improved with home and community management should be followed up by clinic visits on a regular basis to ensure treatment strategies for stable asthma (tailoring up a detailed asthma action plan, checking for proper use of medications, inhaler and peak flow meter, identifying triggers of acute exacerbation, measures of exposure avoidance, and strategy adjustment of controller treatment). For patients whose symptoms do not improve or continue to worsen, emergency visit or hospital admission is necessary. 


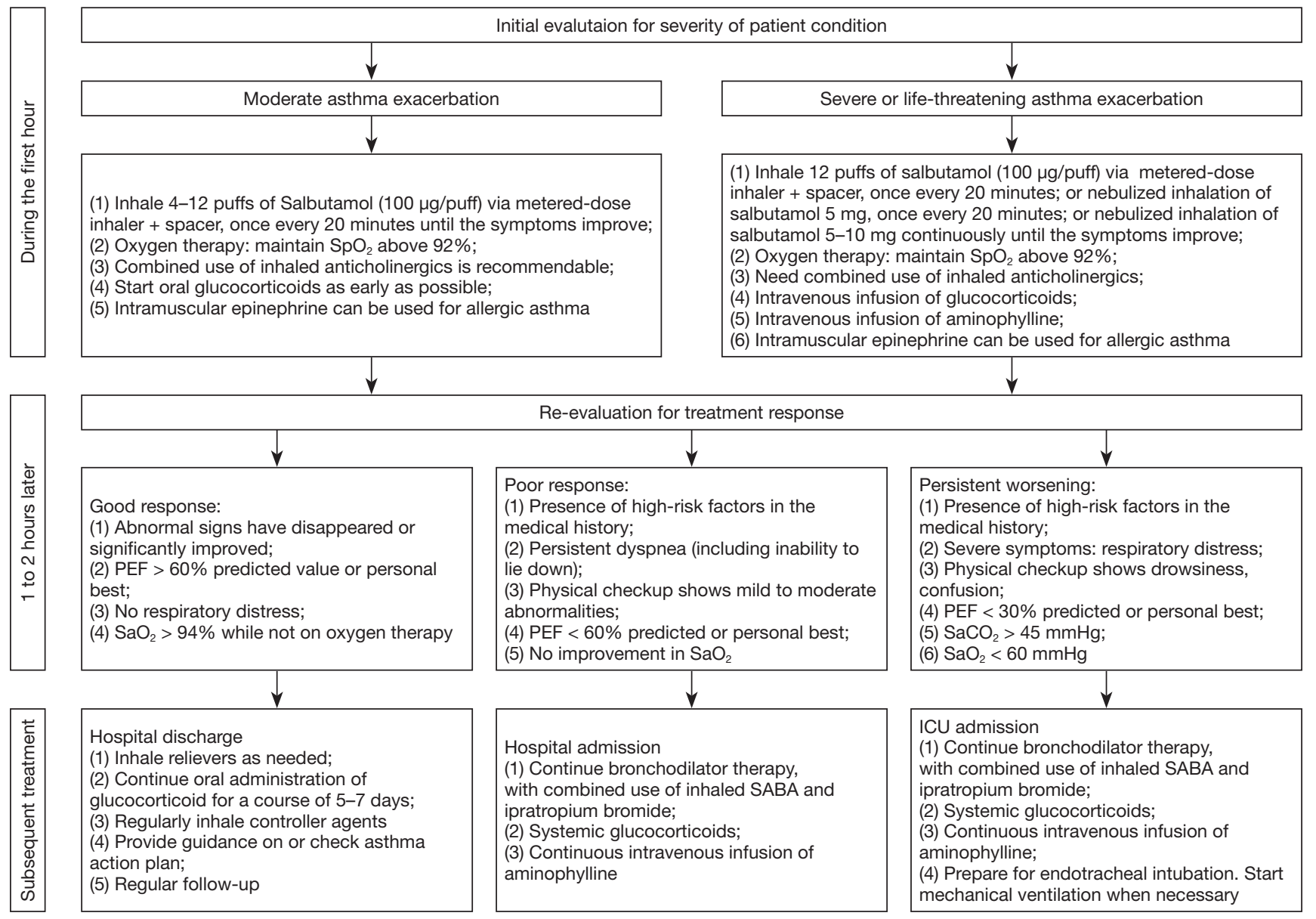

Figure 3 Algorithm for in-hospital treatment of asthma exacerbation. $1 \mathrm{mmHg}=0.133 \mathrm{kPa}$. $\mathrm{PEF}$, peak expiratory flow rate; $\mathrm{SaO}$, arterial oxygen saturation; $\mathrm{PaO}_{2}$, partial arterial pressure of oxygen; $\mathrm{PaCO}_{2}$, partial arterial pressure of carbon dioxide; SABA, short-acting beta2agonist; ICU, intensive care unit.

\section{Algorithm for in-bospital management}

Following admission of a patient with acute exacerbation, physicians should complete the history acquisition, physical checkup (involvement of accessory respiratory muscles, heart rate, respiratory rate and pulmonary auscultation), auxiliary examinations [peak expiratory flow (PEF) or $\mathrm{FEV}_{1}, \mathrm{SpO}_{2}$ monitoring, arterial blood gas analysis], further confirmation on asthma, and initial evaluation of the condition. Patients should be treated immediately as possible with oxygen inhalation, SABA (or in combination with ipratropium bromide), and corticosteroids. Response to treatment is assessed one hour after initial treatment, so that further treatment may be planned accordingly. Figure 3 shows the algorithm of in-hospital management for asthma exacerbation $(30,33,34)$.

\section{Medications}

Medications for routine use in asthma exacerbation include bronchodilators and corticosteroids. As-needed use of less routine medications may be considered for patients whose asthma symptoms remain unresolved after routine medications (35-37).

\section{Bronchodilators}

\section{Beta-2 agonists}

Beta-2 agonists, the most active bronchodilators currently in use, excite the beta- 2 receptors on the membrane surface of airway smooth muscle cells and mast cells. They are capable of symptom-relieving in asthma by relaxing airway smooth muscles, inhibiting degranulation-release of inflammatory mediators from mast cells and basophils, reducing vascular 
permeability, and enhancing the airway ciliary beating.

For selection among a bundle of beta- 2 agonist products, in the case of asthma exacerbation, the action of SABAs (including metered-dose inhalation of salbutamol or terbutaline) appear quickly in minutes and therefore should be considered. These agents exhibit relaxation action on airway smooth muscle which appears in minutes and lasts for hours, and therefore should be the first-line choice for symptom-relief in mild to moderate asthma exacerbation at home or in emergency rooms. SABAs are delivered via pressurized metered-dose inhaler ( $\mathrm{pMDI}$ ) or jet nebulizer. The therapy may start intermittent (every 20 minutes apart) or continuous, and then be given intermittently as needed (once every hours). SABAs given via inhalation is fasteracting and safer compared with oral or intravenous routes. Specifically, salbutamol aerosol is given 2 to 4 puffs initially, repeated every 20 minutes during the first hour. Thereafter, based on assessment of treatment response, the dosing may be titrated to 2 to 4 puffs every 3 to 4 hours for patients with mild exacerbation, and 4 to 8 puffs every 1 to 2 hours for those with moderate exacerbation of asthma. Additional medications are unnecessary provided that the patient responses well to SABA with significant relieve in shortness of breath and $\mathrm{PEF}>80 \%$ predicted or personal best and maintenance of such for 3 to 4 hours. Non-responders to the treatment should visit emergency in due time. Injection preparations of salbutamol may offer quicker anti-asthmatic actions, and therefore can be used for patients with severe asthma exacerbation, faint and shallow breathing, coma, cardiopulmonary arrest, or unrelieved wheezing despite adequate use of inhaled beta- 2 agonists or anticholinergics and/or intravenous theophylline. In these scenarios, an intravenous bolus of $0.2-0.25 \mathrm{mg}$ salbutamol or terbutaline in $40 \mathrm{~mL}$ normal saline may be given slowly (over 15 minutes). Such is not recommended for routine use because of adverse effects, e.g., tachycardia, tremors, and elevated blood pressure.

\section{Anticholinergics}

Inhaled anticholinergics block the postganglionic efferent vagal impulses, hence the bronchodilatory action as a result of lowered vagal tone. Anticholinergics show weaker and slower bronchodilatory effect than beta-2 agonists. Shortacting anticholinergic preparations are available in aerosols and nebulizing solutions. The dosage for ipratropium bromide is 40 to $80 \mu \mathrm{g}, 3$ to 4 times daily via pMDI, or $250 \mu \mathrm{g}, 3$ to 4 times daily via nebulizer. Combination use of anticholinergics and SABA can offer synergistic bronchodilatory effect and, in cases of severe asthma exacerbation, lead to greater improvement in lung function and reduction on hospital admissions compared with monotherapy with bronchodilators $(38,39)$. Use of shortacting anticholinergic agents should be prudent in early pregnancy, glaucoma or benign prostatic hypertrophy.

\section{Theophyllines}

Theophyllines relax the airway smooth muscle, and meanwhile exhibit effects of cardiotonics, diuretics, coronary dilators, central and peripheral respiratory stimulants. A slow intravenous bolus of theophylline in glucose solution is indicated for those with asthma exacerbation who were not given theophyllines in the past $24 \mathrm{~h}$, with a loading dose at 4 to $6 \mathrm{mg} / \mathrm{kg}$ and maintenance dose at 0.6 to $0.8 \mathrm{mg} \cdot \mathrm{kg}^{-1} \cdot \mathrm{h}^{-1}$. The narrow therapeutic window and significant individual difference in metabolism of theophyllines can be associated with adverse events such as arrhythmia, lowered blood pressure, and even death. When accessible, a close watch of serum theophylline level is indispensable to titrate the dosage and infusion rate. Serum theophylline levels should be maintained within the therapeutically effective safety range of 6 to $15 \mathrm{mg} / \mathrm{L}$. A variety of factors may interfere with theophylline metabolism. For instance, the metabolism and excretion of theophyllines are retarded with fever, pregnancy, liver diseases, congestive heart failure, combined use with cimetidine, quinolones, or macrolides, and in these scenarios, theophyllines should be adjusted of the dosage as needed. Intravenous bolus of aminophylline is not recommended. Theophylline exhibits synergistic effects in combination with corticosteroids and anticholinergics. However, in combination with beta-2 agonists, the use of theophyllines may cause tachycardia and arrhythmia, and therefore should be prudent or adjusted for dosing. Doxofylline has similar effects to aminophylline but with significantly milder adverse reactions. Dosage: slow intravenous bolus of $300 \mathrm{mg}$ doxofylline in $100 \mathrm{ml}$ of $5 \%$ glucose or normal saline, given once daily. Diprophylline has weaker effect in bronchodilation but milder adverse reactions compared with aminophylline. Dosage: oral administration of 0.2 to $0.4 \mathrm{~g}$ diprophylline, thrice daily; daily infusion of 1 to $2 \mathrm{~g}$ intravenous diprophylline diluted in $5 \%$ glucose at a rate of 50 to $100 \mathrm{mg} / \mathrm{h}$.

\section{Corticosteroids}

Corticosteroids are currently the most effective antiinflammatory agents and major treatment for moderate to severe asthma exacerbation. They target multiple aspects of the inflammatory responses, i.e., inhibiting gene expression 
of pro-inflammatory cytokines and inflammatory mediators (IL-5, IL-4, and granulocyte-macrophage colonystimulating factor), suppressing the phospholipase $\mathrm{A}_{2}$ activity and reducing production of platelet activating factor $(\mathrm{PAF})$, leukotriene and other inflammatory mediators via inducing lipocortin-1 synthesis. Corticosteroids are capable of reducing microvascular leakage, mucous secretion, inhibiting chemotaxis or activation of inflammatory cells, and enhancing the expression of beta-2 receptors on airway smooth muscle cells, but they do not have direct effects on relaxation of the airway smooth muscles. For asthma exacerbation, corticosteroids are used via inhalation, oral or intravenous use.

\section{Nebulized inhalation of corticosteroids}

ICS (e.g., budesonide suspension) delivered via compressed air or high flow oxygen-driven jet nebulizers, are suitable for asthma exacerbation in terms of low requirements for patient's inspiratory flow pattern and rapid action. Highdose ICS is well tolerated and could partially substitute for systemic corticosteroids and thereby reduce the adverse effects caused by systemic corticosteroids. Dosage: usually 0.5 to $1 \mathrm{mg}$, twice daily; in moderate to severe asthma exacerbation, 1 to $2 \mathrm{mg}$, thrice daily.

\section{Oral use of corticosteroids}

Oral corticosteroids absorb well and basically act as quickly as intravenous corticosteroids, and thus may be used in moderate to severe asthma exacerbation. Recommended dosage: 0.5 to $1.0 \mathrm{mg} / \mathrm{kg}$ prednisone or prednisolone, or equivalent dose of methylprednisolone, taken orally.

\section{Intravenous use of corticosteroids}

Patients with severe asthma exacerbation or unsuitable for oral use should be given corticosteroids via intravenous bolus or infusion in due time. Recommended dosage: 40 to $80 \mathrm{mg} / \mathrm{d}$ methylprednisolone or 400 to $1,000 \mathrm{mg} / \mathrm{d}$ hydrocortisone succinate, given in separate parts. For patients unlikely to become steroid-dependent, the treatment can be discontinued shortly (within 3 to 5 days), otherwise properly prolonged medications may be considered, and switched to oral use when asthma symptoms are under control. Sequential therapy switching from intravenous to oral, for instance, on intravenous preparations for 2 to 3 days followed by oral tablets for 3 to 5 days, may reduce the use of corticosteroids and hence less adverse effects.

Dexamethason, despite its powerful anti-inflammatory effects, should be avoided as possible because of its long half-life in the plasma and tissues, as well as lasting suppression of the hypothalamo-pituitary-adrenal
(HPA) axis.

\section{Medications not recommended for routine use}

For asthma exacerbation that remains uncontrolled with above-mentioned routine treatment, the medications below can be attempted, following adequate communications with the patient and family, close monitoring of the patient condition and vital signs, and with benefits outweighing risks.

\section{Magnesium sulfate}

The therapeutic effects of magnesium sulfate are probably underlain by: (I) reduction of intracellular calcium levels through competitive action with calcium ions, leading to airway smooth muscle relaxation; (II) attenuation of the end-plate depolarization by methacholine, hence lowered muscle fiber excitability in favor of airway smooth muscle relaxation; (III) inhibitory biological effects against histamine release from mast cells, and (IV) sedative effects. Dosage: $10 \mathrm{~mL} 25 \% \mathrm{MgSO}_{4}$ in 250 to $500 \mathrm{~mL}$ glucose solution for intravenous use, at a rate of 30 to $40 \mathrm{drips} / \mathrm{min}$. Administration with magnesium sulfate may improve difficulty breathing, pulmonary function and arterial blood gas in certain patients with severe asthma exacerbations (40). Patients should be monitored for blood pressure and consciousness. The use of magnesium sulfate should be prudent in patients with renal insufficiency and myocardial damage. Favorable treatment outcomes of asthma exacerbation have also been reported with inhalation of magnesium sulfate (41).

\section{Epinephrine}

A subcutaneous bolus of epinephrine $(0.5$ to $1 \mathrm{mg})$ can be used for asthma patients with anaphylactic shock and angioedema. Intravenous epinephrine has been reported to reverse the condition of certain patients in whom severe asthma exacerbation remained unresponsive to adequate use of beta-2 agonists. Dosage: $1 \mathrm{mg}$ epinephrine hydrochloride injection diluted in 500 to $1,000 \mathrm{~mL}$ glucose solution for intravenous infusion at a rate of 15 to $30 \mathrm{drips} / \mathrm{min}$, once or twice daily. The rate of infusion should be titrated against the patient's heart rate and blood pressure. Use of epinephrine is suitable for asthma exacerbation patients aged below 50 years old and with no cardiovascular disorders. Avoid use in combination with alkaline drugs. Do not use in severe hypoxia, arrhythmia, organic heart disease, and hyperthyroidism.

\section{Inhalation of helium-oxygen mixture $\left(\mathrm{He}-\mathrm{O}_{2}\right)$}

$\mathrm{He}-\mathrm{O}_{2}$ mixture may be inhaled via a facial mask at a flow rate of $12 \mathrm{~L} / \mathrm{min}$, with adjustment of oxygen concentration 
to $25-40 \%$ of the mixture depending on severity of hypoxemia. The therapeutic effects may be underlain by: (I) the lower density of gaseous helium as a physical property may give rise to milder airway stricture and less airflow turbulence during asthma exacerbation, resulting in lower airway resistance, less work of breathing, and reduction in oxygen consumption and carbon dioxide $\left(\mathrm{CO}_{2}\right)$ production; (II) the gaseous helium allows for better diffusion and exhalation of $\mathrm{CO}_{2}$, and (III) the gaseous helium improves alveolar ventilation and pulmonary gas exchange $(42,43)$. In China, standardized product of $\mathrm{He}-\mathrm{O}_{2}$ mixture is not yet commercially available.

\section{Antibiotics}

Antibiotics use is not routinely considered for most patients with mild to moderate asthma exacerbation, but should be necessary in severe asthma exacerbation with the following scenarios which can predispose pulmonary infections: (I) bronchial spasm and airway secretions; (II) immunocompromise caused by corticosteroids; (III) reduced neutrophilic chemotaxis and phagocytosis attributable to aminophylline. Recently, antibiotic overuse was revealed in a survey among patients hospitalized due to asthma exacerbation in China. Therefore, indications for antibiotics use should be strictly observed. Follow the principles below when antibiotics are prescribed for asthma patients: (I) usually given intravenously; (II) start by empirical therapy according to local pattern of bacterial resistance pending bacterial culture (e.g., sputum) and susceptibility test, adjusted according to laboratory findings afterwards, and (III) cautioned against adverse effects to liver and kidney function, and possible allergy.

\section{Management of life-threatening asthma exacerbation}

\section{Treatment strategies}

The treatment strategies for life-threatening asthma exacerbation include rapidly resolving bronchospasm, containing airway inflammation, correcting hypoxemia and respiratory failure, timely identification and management of complications. The treatments include use of bronchodilators, systemic corticosteroids, oxygen therapy (maintaining $\mathrm{SaO}_{2}$ above 93\%), and supportive care for respiration.

\section{Medications}

\section{Bronchodilators}

Combined inhalation of beta-2 receptor agonists and anticholinergics may offer better bronchodilatory effects, e.g., $2.5 \mathrm{mg}$ salbutamol or $5 \mathrm{mg}$ terbutaline combined with ipratropium bromide $0.5 \mathrm{mg}$, once every 4 to 6 hours (44). Intravenous and subcutaneous injection of beta-adrenergic receptor agonists can be used for patients on mechanical ventilation or with life-threatening conditions, e.g., subcutaneous bolus of 0.25 to $0.5 \mathrm{mg}$ salbutamol (or $0.25 \mathrm{mg}$ terbutaline), followed by $1 \mathrm{mg}$ salbutamol in $100 \mathrm{ml}$ fluid for intravenous infusion at a rate of 2 to $8 \mu \mathrm{g} / \mathrm{min}$; or subcutaneous bolus of 0.3 to $0.5 \mathrm{mg}$ epinephrine (diluted 1:1,000 to $1 \mathrm{mg} / \mathrm{mL}$ ), followed by $1 \mathrm{mg}$ epinephrine in $500 \mathrm{ml}$ glucose solution for intravenous infusion, once or twice daily, or alternatively, 1 to $2 \mathrm{mg}$ isoproterenol in $500 \mathrm{~mL}$ glucose solution. However, beta-adrenergic receptor agonists should be used with caution in patients with arrhythmia, angina pectoris, and hypertension (45). A slow intravenous bolus ( $\geq 20 \mathrm{~min}$ ) of aminophylline can be given at a loading dose of 4 to $6 \mathrm{mg} / \mathrm{kg}$, followed by a maintenance dose of 0.6 to $0.8 \mathrm{mg} \cdot \mathrm{kg}^{-1} \cdot \mathrm{h}^{-1}$ via intravenous infusion. Doxofylline shows fewer adverse reactions and can be used via intravenous bolus $(0.2 \mathrm{~g} / 12 \mathrm{~h})$ or infusion $(0.3 \mathrm{~g} / 12 \mathrm{~h})$. It should be noted that concomitant use of cimetidine and antibacterials (e.g., macrolides, fluoroquinolones) may reduce the clearance rate of theophyllines (44). Slow intravenous bolus of $25 \%$ magnesium sulfate $5 \mathrm{~mL}$ in $40 \mathrm{~mL}$ glucose solution, or intravenous infusion of $25 \%$ magnesium sulfate $10 \mathrm{~mL}$ in $250 \mathrm{~mL}$ glucose solution, given once daily, may be effective for patients who fail to respond to initial treatment with bronchodilators or with life-threatening asthma exacerbation. Blood pressure should be monitored when using magnesium sulfate (46).

\section{Corticosteroids}

Recommend using 40 to $80 \mathrm{mg} / \mathrm{d}$ methylprednisolone (as an alternative, $10 \mathrm{mg} \cdot \mathrm{kg}^{-1} \cdot \mathrm{d}^{-1}$ hydrocortisone succinate or 0.1 to $0.2 \mathrm{mg} \cdot \mathrm{kg}^{-1} \cdot \mathrm{d}^{-1}$ dexamethasone), generally for 5 to 7 days. Certain patients with life-threatening asthma necessitating high-dose corticosteroids, 160 to $320 \mathrm{mg} / \mathrm{d}$ methylprednisolone or equivalent may be used, tailing out after 1 to 3 days according to the patient condition, with the length of treatment depending on the severity of 
exacerbation and patient response.

\section{Antibiotics}

Antibiotics may be given to patients with severe or lifethreatening asthma exacerbation. The selection depends on disease severity, individual condition, sputum bacterial culture and antibiotic susceptibility.

\section{Mechanical ventilation (46)}

Respiratory supportive care with mechanical ventilation should be given in due time for patients with severe acute exacerbation whose symptoms remain uncontrolled or continue to worsen despite above-mentioned medications. The indications of mechanical ventilation include: severe hypoxemia and/or $\mathrm{CO}_{2}$ retention, respiratory acidosis $(\mathrm{PH}$ $<7.20$ to 7.25 ) and/or severe metabolic acidosis, impaired consciousness, respiratory muscle fatigue, and weakened or ceased spontaneous breathing. The ventilation for patients with severe asthma exacerbation is preferably delivered via orotracheal intubation with a delivery cannula sizing no less than $7.5 \mathrm{~mm}$ by inner diameter.

At the beginning, the ventilator parameters can be set for controlled ventilation $(\mathrm{CV})$ or synchronized intermittent mandatory ventilation (SIMV), with a tidal volume of 6 to $10 \mathrm{~mL} / \mathrm{kg}$, frequency of 8 to 12 times/min, inspiratory/ expiratory ratio (I/E) of 1:2-1:3, inspiratory flow rate of $100 \mathrm{~L} / \mathrm{min}$, and inhalation oxygen concentration of 1.0 (slowly stepped down to 0.6 ), to maintain oxygen saturation $\geq 90 \%$ to $95 \%$. These parameters may be modified according to the treatment responses.

In some cases, additional use of positive end-expiratory pressure (PEEP) may be considered: (I) severe hypoxemia due to complicating pneumonia or acute lung injury; (II) properly additional PEEP is expected to reduce the workload of respiratory muscles in patients who develop severe respiratory muscle fatigue or failure but remain stable in hemodynamics. When adding PEEP, (I) keep it at a low level usually below 10 to $15 \mathrm{cmH}_{2} \mathrm{O}\left(1 \mathrm{cmH}_{2} \mathrm{O}\right.$ equals to $0.098 \mathrm{kPa}$ ), and the level of PEEP should be lower than that of auto-PEEP; (II) do not use for a long time, usually for 20 to 30 minutes within which the intended effects should appear, disused otherwise.

On mechanical ventilation, sedatives and/or muscle relaxants may be properly given when the patient developed agitation, delirium, man-machine confrontation, or serious bronchospasm. The options of sedative use may be intravenous bolus of: 10 to $20 \mathrm{mg}$ diazepam or
$50 \mathrm{mg}$ ketamine; 1 to $2 \mathrm{mg} / \mathrm{kg}$ disoprofol, at a rate of $0.5 \mathrm{mg} \cdot \mathrm{kg}^{-1} \cdot \mathrm{min}^{-1}$; or propofol, at a rate of 0.1 to $0.5 \mathrm{mg} / \mathrm{h}$. The commonly-used muscle relaxant is Vecuronium bromide, given by intravenous bolus at a dose of 0.08 to $0.1 / \mathrm{kg}$, and then maintained at a dose of 0.01 to $0.015 \mathrm{mg} / \mathrm{kg}$.

\section{Correction of fluid-electrolyte and acid-base imbalances}

Correct dehydration, humidify the airway, and prevent formation of mucus and sputum plugs. The volume of daily infusion should be 2,500 to $4,000 \mathrm{~mL}$, to allow for a urine output of $1,000 \mathrm{~mL}$ or above. Bronchoalveolar lavage can be used to address the airway mucus plugs when necessary. Acid-base imbalance and electrolyte disturbance should be identified and corrected early. In uncomplicated respiratory acidosis, alkaline replacement ( $5 \%$ sodium bicarbonate) may be initiated with the $\mathrm{pH}$ value $<7.20$ and stopped when $\mathrm{pH}>7.20$; however, in mixed acidosis, alkaline replacement should continue to reach a $\mathrm{pH}>7.30$. In parallel, serum electrolytes and blood glucose should be monitored for possible hyperkalemia and hyperglycemia caused by the use of beta- 2 adrenergic receptor agonists and corticosteroids.

\section{Special considerations for treatment of asthma exacerbation}

\section{During perioperative period}

The perioperative period generally refers to a time period between 5 to 7 days prior to, and 7 to 12 days after surgery. The treatment principles for perioperative asthma exacerbation should focus on proactive response to risk factors of perioperative onset, early identification and timely treatment of intraoperative asthma exacerbation, and postoperative management of asthma.

\section{Risk factors of perioperative onset of asthma exacerbation}

(I) uncontrolled asthma, seen in asthma patients not on regular medications, with moderate to severe disease, a recent episode of exacerbation, or concomitant upper airway infection; (II) irritations at anesthesia and surgery (47), such as intubation, extubation and sputum suction under light anesthesia, overly deep insertion of the endotracheal catheter, and irritations from surgical manipulations; (III) certain medications (48-50), including the vagus-stimulating thiopental and gamma-hydroxybutyrate, the histamine release-inducing tubocurarine, atracurium and micuronium, 
and other drugs (e.g., ethyl ether); (IV) psychological factors such as worry and fear $(47,50)$.

\section{Diagnosis and management of intraoperative asthma exacerbation \\ Diagnosis (51,52)}

(I) patients with a history of asthma, or suspected of asthma with presentations of recurrent wheezing, coughing and chest tightness; (II) prolonged expiratory phase, decreased range of chest wall motion, wheezing or vanished breathing sounds over the both lungs on auscultation; (III) persistent falls in $\mathrm{SpO}_{2}$; (IV) evidenced increase in peak airway pressure; (V) exclusion of complications arising from a twisted catheter, allergies, pulmonary edema, aspiration, and thromboembolism.

\section{Treatment}

(I) Eliminate causative factors, and suspend surgery if necessary; (II) deliver assisted ventilation (AV) or CV; when oxygenation remains abnormal with facial mask, prompt for endotracheal intubation with higher-flow oxygen therapy; (III) medications, given as in practices for asthma exacerbation under usual occasions, include nebulized inhalation of SABA alone or in combination with shortacting muscarinic antagonist (SAMA), corticosteroids and theophylline use for relieving bronchospasm (52), with correction of hypoxia, and fluid-electrolyte imbalance.

\section{Postoperative management of asthma (30)}

Breathing exercise, proper analgesia and containment of gastroesophageal reflux after surgery may reduce asthma exacerbations. Non-invasive positive pressure ventilation may be beneficial in asthma patients who develop persistent airway spasm after extubation.

\section{During pregnancy}

Asthma exacerbations during pregnancy may cause hypoxia to the mother and fetus. A partial oxygen pressure $\left(\mathrm{PaO}_{2}\right)$ below $60 \mathrm{mmHg}(1 \mathrm{mmHg}$ equals to $0.133 \mathrm{kPa})$ or $\mathrm{SpO}_{2}$ $<90 \%$ can give rise to a variety of conditions, including preeclampsia, premature rupture of amniotic membrane, preterm birth, low-birth-weight infants, intrauterine growth retardation, small-for-gestational-age infants, still-birth (53-55), and therefore should warrant aggressive response.

\section{Treatment at home}

Early identification of asthma exacerbations helps to take active measures. Asthma exacerbation may be manifested mainly by worsening of the symptoms, but does not correlate well in severity with the latter, rendering necessity for monitoring of PEF and fetal activity (progressive reduction in counting of fetal movements over time). Reduction in PEF by $>20 \%$ and in fetal movements can be reflective of the asthma exacerbation. Initially, selfmanagement is allowable, by following the specific steps and medications as in non-pregnancy related asthma. A quick resolution in symptoms, $\mathrm{PEF}>80 \%$ predicted, and normality-resuming of the fetal movements suggest effective treatment response, then the patient should visit hospital for adjustment of medications. Unsatisfactory improvement or even worsening in either PEF or fetal movements, regardless of the above treatment, should prompt for immediate emergency visit.

\section{Treatment in hospital}

The goal of in-hospital treatment is to avert hypoxia in the mother and fetus, by following the specific steps and medications as in non-pregnancy related asthma. All pregnant women should be given oxygen therapy, aided with continuous $\mathrm{SpO}_{2}$ and fetal monitoring, to maintain $\mathrm{SpO}_{2} \geq 95 \%$. Aggressive use of SABA and ICS is recommendable. Use additional oral corticosteroids for poor responders, intravenous corticosteroids for those who develop respiratory failure, and inhaled anticholinergics as an add-on therapy to SABA for patients with severe asthma exacerbation $(56,57)$. After the first (several minutes) and three doses (60 to 90 minutes) of bronchodilator use, the patient should be evaluated for pulse rate, involvement of the accessory respiratory muscles, wheezing, $\mathrm{FEV}_{1}$ or PEF, and fetal monitoring. Chest $\mathrm{X}$-ray is not part of routine examination.

\section{Treatment during delivery}

During the delivery, although asthma usually relieves, the medications and PEF monitoring should continue. For mothers who received systemic corticosteroids within four weeks prior to delivery, intravenous hydrocortisone succinate at a dose of $100 \mathrm{mg} / 8 \mathrm{~h}$ (or methylprednisolone equivalent) should be used to prevent adrenal crisis (58). A change to the delivery mode is not mandatory, which is in the common discretion of obstetricians, anesthesiologists and pediatricians who attend the patient. Prostaglandins $\mathrm{E}_{2}$ and $\mathrm{E}_{1}$ may offer benefits in cervical ripening and postpartum hemostasis; however, use of 15-methyl PGF2-alpha and methyl ergometrine may cause bronchospasm. Magnesium sulfate and terbutaline exhibit 
bronchodilatory effects, and may be used for prevention of miscarriage. Indomethacin may induce bronchospasm in pregnant women allergic to aspirin. The role of calcium antagonists in preventing miscarriage has not been reported in the literature. In Caesarean section, use of epidural anesthesia could help reduce oxygen consumption and minute ventilation during the delivery (58). Pethidine may promote histamine release but seldom lead to bronchospasm. Topical anesthesia causes bronchial constriction in $2 \%$ of the times (59).

\section{During childhood}

In this period of rapid growth and development, the diagnosis, treatment and prognosis of childhood asthma varies with those aspects in adults. Although the assessment criteria for severity of childhood asthma exacerbation are similar with those in adults (30), the role of lung function test appears limited in evaluating asthma, due to poor compliance of the testing in younger children. Attentions should be given to the changes in mental condition, speech, involvement of accessory respiratory muscles, $\mathrm{SpO}_{2}$ and wheezing sounds on auscultation (60). In children with severe asthma exacerbation, absence of wheezing sounds (clinically termed as silent lung) may suggest a critical scenario. The severity of asthma exacerbations in children aged $<6$ years old is classified as mild, moderate, or severe, and in children aged $>6$ years old, as mild, moderate, severe or life-threatening, depending on clinical symptoms and lung function tests.

The treatment for childhood asthma exacerbation targets at prompt resolution of airway obstruction and hypoxemia, and prevention of future relapse. The treatment and management should be a sequential process to cover the early self-management and treatments in medical institutions. A group of premonitory symptoms (e.g., runny nose, sneezing and coughing) usually prelude childhood asthma exacerbations (61), and when these appears, inhaled budesonide $1 \mathrm{mg}$, given twice daily for consecutively 7 days, has been shown to reduce asthma exacerbation and emergency visits (62). Inhaled SABA is the firstline treatment for asthma exacerbations in children (60). Combined bronchodilator and ICS offers greater benefits than bronchodilator alone in the exacerbations, with effectively reduced hospital admission and use of systemic corticosteroid (60). For severe asthma exacerbations, early systemic corticosteroids may relieve the severity of condition in children, recommended to be given orally or intravenously $(60,63)$. Anticholinergic agents are part of combination therapy in children with asthma exacerbation, and should be started early especially in those with moderate to severe asthma who fail to respond adequately to beta- 2 receptor agonists (60). Intravenous magnesium sulfate may effectively alleviate the symptoms of severe asthma with a favorable safety profile (64). Intravenous use of theophylline is not recommended as a routine treatment of asthma exacerbation (60). Assisted ventilation should be initiated at signs of respiratory failure.

Majority of patients with childhood asthma should be on sustained, regular ICS. A single onset of severe asthma exacerbation is a risk factor for future episodes (evidence level B). Treatment regimens containing ICS may significantly decrease the risks of asthma-related death and hospital admission (evidence level A) (1). Standard antiinflammatory therapy is necessary after asthma exacerbation in children.

\section{Complications and related management}

\section{Respiratory failure}

The airway obstruction and hypoxemia during asthma attacks could lead to type I respiratory failure; along with progression of the condition, $\mathrm{CO}_{2}$ retention, type II respiratory failure, and respiratory acidosis may occur. These render early arterial blood gas analysis warranted. According to blood gas analysis, patients with type I respiratory failure should be given systemic corticosteroids and inhaled SABA, while under a close watch for treatment response and serial change in blood gases; those with type II respiratory failure may be of critically-ill cases. In these scenarios, if the symptoms remain unrelieved, and blood gas analysis shows progressively increasing $\mathrm{PaCO}_{2}$, mechanical ventilation should be considered.

\section{Mucus plugging and atelectasis}

During severe asthma exacerbation, there is a dramatic increase in mucosecretion. The open-mouth breathing and excessive sweating in the patients may result in overly depletion of body fluids, adding to hyper-viscosity of mucous secretions and significantly impaired mucociliary transport. Overall, these contribute to bronchiolar obstruction by mucus plugging, which, together with presence of bronchial wall thickening, mucosal congestion 
and edema, leads to pulmonary atelectasis.

\section{Pneumothorax and mediastinal emphysema}

Patients with asthma exacerbation may develop spontaneous pneumothorax due to rupture of pulmonary bullae caused by hyperinflation and elevated pressure in the lungs. Likewise, the air could escape to infiltrate the lung interstitial tissues, migrate along bronchial vascular bundles to the hilum then into the mediastinum, and finally give rise to mediastinal emphysema. Following onset of pneumothorax, thoracocentesis or closed thoracic drainage should be performed immediately. Patients with mild mediastinal emphysema may be given oxygen therapy; in extreme cases complicated with subcutaneous emphysema and cardiopulmonary dysfunction, an incision over the suprasternal notch is suggested for air drainage and decompression.

\section{Fluid-electrolyte disturbance and acid-base imbalance}

Asthma exacerbation is usually accompanied by fluidelectrolyte disturbance and acid-base imbalance as a result of hypoxia, underfeeding, and excessive fluid loss. Monitor electrolytes and arterial blood gases, and address accordingly in time of abnormal findings.

\section{Arrbythmia}

Arrhythmia may arise from hypoxia, fluid-electrolyte disturbance, and acid-base imbalance in severe asthma exacerbation. Therefore, early in the treatment, aggressive measures should be taken against hypoxia, fluid-electrolyte disturbance, acid-base imbalance and dehydration. On the other hand, arrhythmia may also be associated with use of beta-2 receptor agonists and theophylline.

\section{Sudden death}

Sudden death, the most serious complication of asthma exacerbation, usually occurs without premonitory symptoms, deteriorates abruptly and in most of death case, does not temporally allow for rescue. Therefore, it is critical to identify patients at high-risk for asthmarelated death. For these patients, self-management at the onset of asthma exacerbation should be necessary, and then followed by visits to medical institutions immediately.

\section{Hospital discharge and follow-up}

\section{Criteria for hospital discharge:}

* Symptomatic relief;

* Clinical stability with improved lung function;

* No comorbidities and/or complications that require hospital stay.

\section{Follow-up}

The follow-up for patients should be on a regular basis within one month after hospital discharge and, with symptoms well under control and the lung function resuming pre-episode level, may be set with properly extended intervals of 1 to 3 months. Each follow-up session should focus on the following issues: (I) evaluating symptom control and adjusting the treatment regimen accordingly; (II) looking for possible causative and predisposing factors of asthma exacerbations, and recommending on effective avoidance; (III) assessing treatment adherence and proper use of inhaler techniques, with emphasis and corrections if applicable; (IV) tailoring up or validating a written asthma action plan for the patient (1).

\section{Prognosis}

\section{Impacts of asthma exacerbation to the host}

Onset of asthma usually originates early in infancy. As reported in a number of studies, children with persistent asthma are subject to the risk of under-developed or earlydeclining lung function, with normal development of lung function found in only $25 \%$ of the cases (65). In these children, recurrent airway infections induced by exogenous pathogenic factors may lead to asthma exacerbation, which in turn adds to the risk of refractory asthma and chronic obstructive pulmonary disease later in life. Future studies should therefore focus specifically on the field of pediatric respiratory medicine. Nearly $3 \%$ to $5 \%$ of the children with recurrent asthma exacerbation would subsequently develop severe asthma which features poor symptom control, frequent severe exacerbations and extremely serious airflow limitation (66). Severe asthma accounts for 15 and 20 times, respectively, the frequency of emergency visit and hospital admission as in mild and moderate asthma, representing the major cause of increased asthmarelated medical costs, mortality and disability. Asthma exacerbation imposes a huge socioeconomic burden, but so 
far, optimal management options for patients with frequent asthma exacerbation are yet to be refined. Further studies are warranted to improve the practices of diagnosis and treatment through predicting asthma exacerbation and identifying relevant biomarkers.

\section{Prognosis}

Given the diversity in manifestations, duration and severity, the clinical outcome and prognosis of asthma exacerbation also vary among patients, generally recognized as: (I) in most cases, asthma exacerbation presents as a transient and mild episode that may resolve spontaneously or after treatment, ending up with recovery to the pre-episode condition; (II) in certain cases, asthma exacerbation can be poorly responsive to treatment and remain unresolved for hours or even days, necessitating endotracheal intubation and mechanical ventilation; comorbidities may be present; (III) in fewer occasions, asthma exacerbation in a patient who otherwise is with modest symptoms and unremarkable lung function, can progress to respiratory failure within a short period of time, i.e., a life-threatening scenario termed as sudden-onset fatal asthma; (IV) asthma exacerbation in patients with long-standing, severe and poorly-controlled asthma further deteriorates the impaired lung function and, with increased risk of further relapse, appears difficult to resume the pre-episode status.

So far there have been no recognized indicators to predict the treatment response and prognosis for asthma exacerbation. In 2013, a large multicenter clinical study on severe asthma exacerbation led by Goodacre et al. (67) demonstrated that, PEF rate variability and heart rate at baseline and 2 hours after treatment, and comorbidity with other severe diseases, are independent predictors of treatment failure. In 2016, a study recruiting 973 asthmatic children referred to emergency departments, identified treatment failure in $17 \%$ of all cases. The investigators found that nasopharyngeal viruses, fever, baseline Pediatric Respiratory Assessment Measure (PRAM) score and $\mathrm{SpO}_{2}$ $<92 \%$ were associated with failure of management, while viral infection was an independent risk factor (68). In summary, unsatisfactory asthma control, poor lung function at baseline, long-standing symptoms prior to hospital visit, advanced age or physical debilitation, comorbidity with COPD and other chronic diseases, and concomitant conditions such as bacterial and viral infections, pneumothorax, mediastinal emphysema, usually point to a poor prognosis. Accurate assessment of asthma severity, identification of patients at the risk of death, early and aggressive interventions, and personalized therapy following a well-defined algorithm, are critical to regress disease progression and reduce asthma exacerbation. It is therefore considerably important to initiate asthma action plan and controller treatment immediately following an asthma exacerbation, so as to reduce the risk of future relapse. In 2015, a retrospective study on asthma relapse after emergency visits demonstrated recurrence of exacerbation in $18 \%$ of asthmatic adults within 4 weeks following treatment in the emergency department, especially, those with severe condition and in need of systemic corticosteroids or ICS/ long-acting beta-2 receptor agonists (LABAs) (69).

\section{Death-related risk factors}

Patients who present the following factors are at a greater risk of death (1), including: (I) a history of fatal asthma onsets that require endotracheal intubation and mechanical ventilation; (II) a history of hospital stay or emergency visit for asthma during the previous year; (III) on use of oral corticosteroids currently or until recently; (IV) not currently on ICS; (V) excessive use of SABA, esp. by consuming more than one salbutamol inhaler per month; (VI) a history of mental disorders; (VII) poor adherence to medications; and (VIII) food allergies.

\section{Acknowledgments}

This consensus document was translated from a Chinese version by Dr. Prof. Guangqiao Zeng and his colleagues (Chu Pei, Rui Wang and Kangni Chen), with permission and authorization from Prof. Jiang-Tao Lin on behalf of China Asthma Alliance. The translators aim to promote and distribute this consensus to a wider international scientific audience.

Funding: This work was supported by the Capital Key Science Program for Health Development (2016-1-4061); Beijing Science and Technology Commission Capital Key Program for Clinical Application Research (2015-BKJ-001).

\section{Footnote}

Conflicts of Interest: The authors have no conflicts of interest to declare.

Ethical Statement: The authors are accountable for all aspects of the work in ensuring that questions related 
to the accuracy or integrity of any part of the work are appropriately investigated and resolved.

\section{References}

1. GINA Executive and Science Committee. Global Strategy for asthma management and prevention 2017. [2017-0909]. Available online: http://www.gina.com

2. Lin J. To achieve optimum asthma control is the core of implementing effective asthma management. Zhonghua Nei Ke Za Zhi 2014;53:594-5.

3. Lin JT, Xing B, Tang HP, et al. A multi-center retrospective study of clinical characteristics and hospitalization costs of patients hospitalized for asthma exacerbation in China during 2013-2014. Zhonghua Jie He He Hu Xi Za Zhi 2017;40:830-4.

4. Lin J, Feng X. Paying greater attention to the studies of disease burden of bronchial asthma. Zhonghua Yi Xue Za Zhi 2014;94:1201-3.

5. Lin JT, Xing B, Wang WQ. Pay attention to the characteristics of asthma exacerbations, and improve the self-management level of the patients. Zhonghua Yi Xue Za Zhi 2017;97:2321-3.

6. The Asthma Workgroup, Chinese Thoracic Society. Guideline for bronchial asthma prevention and treatment (definition, diagnosis, treatment and management of bronchial asthma). Zhonghua Jie He He Hu Xi Za Zhi 2008;31:177-85.

7. Reddel HK, Taylor DR, Bateman ED, et al. An official American Thoracic Society/European Respiratory Society statement: asthma control and exacerbations: standardizing endpoints for clinical asthma trials and clinical practice. Am J Respir Crit Care Med;2009,180:59.

8. Pauwels RA, Pedersen S, Busse WW, et al. Early intervention with budesonide in mild persistent asthma: a randomised, double-blind trial. Lancet 2003;361:1071-6.

9. Reddel H, Ware S, Marks G, et al. Differences between asthma exacerbations and poor asthma control. Lancet 1999;353:364-9.

10. Lin J, Xing B, Tang H, et al. Seasonal characteristics of patients hospitalized for asthma exacerbation in China Zhonghua Yi Xue Za Zhi 2017;97:2324-8.

11. Singh AM, Busse WW. Asthma exacerbations.2: aetiology. Thorax 2006;61:809-16.

12. Xing B, Lin J, Tang H, et al. A retrospective study of the inducing factors and clinical characteristics of patients hospitalized for asthma exacerbation in China in 20132014. Zhonghua Nei Ke Za Zhi 2018;57:21-6.
13. Johnston SL, Pattemore PK, Sanderson G, et al. Community study of role of viral infections in exacerbations of asthma in 9-11 year old children. BMJ 1995;310:1225-9.

14. Osborne ML, Pedula KL, O'Hollaren M, et al. Assessing future need for acute care in adult asthmatics: the profile of asthma risk study: a prospective health maintenance organization-based study. Chest 2007;132:1151-61.

15. Lange P, Parner J, Vestbo J, et al. A15-yearfollow-upstudy of ventilatory function in adults with asthma. $\mathrm{N} \mathrm{Engl} \mathrm{J}$ Med 1998;339:1194-200.

16. Lazarus SC, Chinchilli VM, Rollings NJ, et al. Smoking affects response to inhaled corticosteroids or leukotriene receptor antagonists in asthma. Am J Respir Crit Care Med 2007;175:783-90.

17. Chaudhuri R, Livingston $\mathrm{E}, \mathrm{Mcmahon} \mathrm{AD}$, et al. Cigarette smoking impairs the therapeutic response to oral corticosteroids in chronic asthma. Am J Respir Crit Care Med 2003;168:1308-11.

18. Jie $\mathrm{Y}$, Ismail NH, Jie X, et al. Do indoor environments influence asthma and asthma-related symptoms among adults in homes?: a view of the literature. J Formos Med Assoc 2011;110:555-63.

19. Jenerowicz D, Silny W, Dańczakpazdrowska A, et al. Environmental factors and allergic diseases. Ann Agric Environ Med 2012;19:475-81.

20. Mapp CE, Boschetto P, Maestrelli P, et al. Occupational asthma. Am J Respir Crit Care Med 2005;172:280-305.

21. Chen $P, Z h u W$. The etiology and diagnosis of occupational asthma. Chinese Journal of Practical Internal Medicine 2009;29:299-301.

22. Weiler JM, Anderson SD, Randolph C, et al. Pathogenesis, prevalence, diagnosis, and management of exerciseinduced bronchoconstriction: a practice parameter. Ann Allergy Asthma Immunol 2010;105:S1-47.

23. Yang F, Lin J. Recent progress of exercise-induced asthma treatment. Journal of China-Japan Friendship Hospital 2007;21:247-9.

24. Busse WW. The brain and asthma: what are the link ages? Chem Immunol Allergy 2012;98:14-31.

25. Rao CK, Moore CG, Bleecker E, et al. Characteristics of perimenstrual asthma and its relation to asthma severity and control: data from the severe asthma research program. Chest 2013;143:984-92.

26. Murphy VE, Gibson PG. Asthma in pregnancy. Clin Chest Med 2011;32:93-110.

27. Fraenkel DJ, Bardin PG, Sanderson G, et al. Lower airways inflammation during rhinovirus colds in normal 
and in asthmatic subjects. Am J Respir Crit Care Med 1995;151:879-86.

28. Price DB, Rigazio A, Campbell JD, et al. Blood eosinophil count and prospective annual asthma disease burden: a UK cohort study. Lancet Respir Med 2015;3:849-58.

29. Lin JT, Wang W, Zhou X, et al. Warning symptoms of asthma attack and asthma self-management: a national asthma control survey from China. Zhonghua Yi Xue Za Zhi 2017;97:2329-32.

30. The Asthma Workgroup, Chinese Thoracic Society. Guideline for the diagnosis and treatment of bronchial asthma (2016). Zhonghua Jie He He Hu Xi Za Zhi 2016;39:675-97.

31. Alangari AA. Corticosteroids in the treatment of acute asthma. Ann Thorac Med 2014;9:187-92.

32. Edmonds ML, Camargo CA Jr, Pollack CV, et al. Early use of inhaled corticosteroids in the emergency department treatment of acute asthma. Cochrane Database Syst Rev 2003;(3):CD002308.

33. Ichinose M, Sugiura H, Nagase H, et al. Japanese guidelines for adult asthma 2017. Allergol Int 2017;66:163-89.

34. National Asthma Council Australia. National Asthma Council Australia, Australian Asthma Handbook, Version 1.2 [M/OL]. Melbourne: National Asthma Council Australia, (2016) [2017-0909]. Available online: http:// www.asthmahandbook.org.au

35. Yin K. Refractory respiratory disease. Shanghai: Shanghai Scientific \& Technical Publishers; 2007:307-27.

36. Braganza G, Thomson NC. Acute severe asthma in adults. Medicine 2008;36:209-12.

37. Albertson TE, Sutter ME, Chan AL. The acute management of asthma. Clin Rev Allergy Immunol 2015;48:114-25.

38. Rodrigo GJ, Castrorodriguez JA. Anticholinergics in the treatment of children and adults with acute asthma: a systematic review with meta-analysis. Thorax 2005;60:740-6.

39. Kirkland SW, Vandenberghe C, Voaklander B, et al. Combined inhaled beta-agonist and anticholinergic agents for emergency management in adults with asthma. Cochrane Database Syst Rev 2017;1:CD001284.

40. Nie H, Cao Y. Magnesium Sulfate management of severe asthma in China. Zhonghua Jie He He Hu Xi Za Zhi 2001;24:137-8.

41. Jiang S, Zeng Z, Li Y, et al. Inhaled Magnesium Sulfate on pulmonary function in asthma exacerbation. Zhonghua Jie He He Hu Xi Za Zhi 2001;24:699-700.

42. Rodrigo GJ. Advances in acute asthma. Curr Opin Pulm
Med 2015;21:22-6.

43. Rodrigo GJ, Castro-Rodriguez JA. Heliox-driven $\beta 2$ agonists nebulization for children and adults with acute asthma: a systematic review with meta-analysis. Ann Allergy Asthma Immunol 2014;112:29-34.

44. Green E, Jain P, Bernoth M. Noninvasive ventilation for acute exacerbations of asthma: asystematic review of the literature. Aust Crit Care 2017;30:289-97.

45. Sellers WF. Inhaled and intravenous treatment in acute severe and life-threatening asthma. Br J Anaesth 2013;110:183.

46. Rowe BH, Bretzlaff J, Bourdon C, et al. Magnesium sulfate for treating exacerbations of acute asthma in the emergency department. Cochrane Database Syst Rev 2000;9:CD001490.

47. Trueba AF, Simon E, Auchus RJ, et al. Cortisol response to acute stress in asthma: moderation by depressive mood. Physiol Behav 2016;159:20-6.

48. Vaschetto R, Bellotti E, Turucz E, et al. Inhalational anesthetics in acute severe asthma. Curr Drug Targets 2009; 10:826-32.

49. Mirone C, Preziosi D, Mascheri A, et al. Identification of risk factors of severe hypersensitivity reactions in general anaesthesia. Clin Mol Allergy 2015;13:11.

50. Rosenkranz MA, Esnault S, Christian BT, et al. Mindbody interactions in the regulation of airway inflammation in asthma: a PET study of acute and chronic stress. Brain Behav Immun 2016;58:18-30.

51. Li Q, Kong L. The treatment of bronchial asthma in perioperative period. Chinese Journal of Practical Internal Medicine 2009;29:297-99.

52. Woods BD, Sladen RN. Perioperative considerations for the patient with asthma and bronchospasm. Br J Anaesth 2009;103 Suppl1:i57-65.

53. Gordon M, Niswander KR, Berendes H, et al. Fetal morbidity following potentially anoxigenic obstetric conditions. VII. bronchial asthma. Am J Obstet Gynecol 1970;106:421-9.

54. Warrell DW, Taylor R. Outcome for the foetus of mothers receiving prednisolone during pregnancy. Lancet 1968;1:117-8.

55. Gelber M, Sidi Y, Gassner S, et al. Uncontrollable life-threatening status asthmaticus--an indicator for termination of pregnancy by cesarean section. Respiration 1984;46:320-2.

56. Rodrigo GJ, Rodrigo C. The role of anticholinergics in acute asthma treatment: an evidence-based evaluation. Chest 2002;121:1977. 
57. U.S. Department of Health and Human Services; National Institutes of Health; National Heart, Lung, and Blood Institute. Guidelines for the diagnosis and treatment of asthma (EPR-2). [2019-12-15]. Available online: http:// www.nhlbi.nih.gov/guidelines/asthma/asthgdln.htm

58. Hägerdal M, Morgan CW, Sumner AE, et al. Minute ventilation and oxygen consumption during labor with epidural analgesia. Anesthesiology 1983;59:425-7.

59. Fung DL. Emergency anesthesia for asthma patients. Clin Rev Allergy 1985;3:127-41.

60. Subspecialty Group of Respiratory Diseases, Society of Pediatrics, Chinese Medical Association; Editorial Board, Chinese Journal of Pediatrics. Guideline for the diagnosis and optimal management of asthma in children (2016). Zhonghua Er Ke Za Zhi 2016;54:167-81.

61. Velissariou IM, Papadopoulos NG. The role of respiratory viruses in the pathogenesis of pediatric asthma. Pediatr Ann 2006;35:637-42.

62. Zeiger RS, Mauger D, Bacharier LB, et al. Daily or intermittent budesonide in preschool children with recurrent wheezing. N Engl J Med 2011;365:1990-2001.

63. British Thoracic Society, Scottish Intercollegiate Guidelines Network. British guideline on the management of asthma. Thorax 2014;69 Suppl1:1-192.

64. Singhi S, Grover S, Bansal A, et al. Randomised comparison of intravenous magnesium sulphate, terbutaline and aminophylline for children with acute severe asthma. Acta Paediatrica 2014,103:1301-6.

65. McGeachie MJ, Yates KP, Zhou X, et al. Patterns of growth and decline in lung function in persistent childhood asthma. N Engl J Med 2016;374:1842.

66. Chung KF, Wenzel SE, Brozek JL, et al. International ERS/ ATS guidelines on definition, evaluation and treatment of severe asthma. Eur Respir J 2014,43:343-73.

67. Goodacre S, Bradburn M, Cohen J, et al. Prediction of unsuccessful treatment in patients with severe acute asthma. Emerg Med J 2014;31:e40-45.

68. Ducharme FM, Zemek R, Chauhan BF, et al. Factors associated with failure of emergency department management in children with acute moderate or severe asthma: a prospective, multicentre, cohort study. Lancet Respir Med 2016;4:990-8.

69. Rowe BH, Villa-Roel C, Majumdar SR, et al. Rates and correlates of relapse following ED discharge for acute asthma: a Canadian 20-site prospective cohort study. Chest 2015;147:140-9.
Cite this article as: Lin J, Xing B, Chen P, Huang M, Zhou X, Wu C, Yang D, Yin K, Cai S, Cheng X, Hao C, Wang C, Liu C; on behalf of China Asthma Alliance. Chinese expert consensus-based guideline on assessment and management of asthma exacerbation. J Thorac Dis 2019;11(12):4918-4935. doi: 10.21037/jtd.2019.12.67 